This is a postprint version of the following published document:

Herrero, M.; Martos, A.M.; Varez, A.; Galván, J.C.; Levenfeld, B. Synthesis and characterization of polysulfone/layered double hydroxides nanocomposite membranes for fuel cell application. International Journal of Hydrogen Energy, vol. 39, issue 8 (March 2014), pp. 4016-4022

(C) 2013, Hydrogen Energy Publications, LLC. Published by Elsevier Ltd. All rights

DOI: $10.1016 /$ j.ijhydene.2013.06.041 


\title{
Synthesis and characterization of polysulfone/ layered double hydroxides nanocomposite membranes for fuel cell application
}

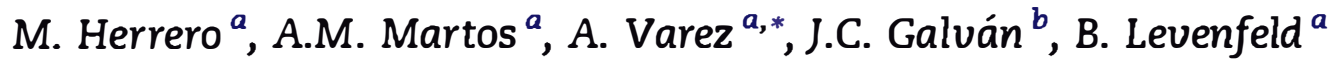 \\ a Departamento de Ciencia e Ingeniería de Materiales e Ingeniería Quimica, Universidad Carlos III de Madrid, \\ Avenida de la Universidad, 30, 28911 Leganés, Madrid, Spain \\ ${ }^{b}$ Centro Nacional de Investigaciones Metalúrgicas (CENIM CSIC), Avda. Gregorio del Amo, 8, 28040 Madrid, Spain
}

Keywords:

PEM

Polysulfone

Layered double hydroxide

Proton conductivity

\begin{abstract}
A B S T R A C T
In the present study, sulfonated polysulfone (SPSU)/layered double hydroxide (LDH) composite membranes for use in proton exchange membrane fuel cells (PEMFCs) were investigated. Polysulfone (PSU) was sulfonated with trimethylsilyl chlorosulfonate in 1,2 dichloroethane at room temperature.

Composite membranes were prepared by blending different amount $(0,1,2$, and $5 \%)$ of LDH nanoparticles with SPSU in dimethylacetamide (DMAC). The membranes were pre pared by the casting method and the samples obtained were characterized by XRD, FTI R spectroscopy. The thermal behavior for all samples was evaluated by thermogravimetrical analysis (TGA). Finally electrochemical impedance spectroscopy (EIS) was used to study the membranes electrical properties. The EIS measurements were carried out with the mem

branes in contact with $\mathrm{HCl}$ solutions at different concentrations $\left(10^{3} \leq \mathrm{c} \leq 10^{1}\right)$. Results show a clear dependence of the membrane electrical resistance with the sulfonation degree and the amount of the LDH added.
\end{abstract}

\section{Introduction}

In the last years, great effort has gone into the fuel cells development in order to avoid the dependence on hydrocar bon fuel and the pollution release during the process which can be cause hazardous threat to the environment and human life. The most promising fuel cells are the polymer electrolyte membrane fuel cells (PEMFCs) due their modularity [1] and wide variety of applications. In PEMFCs a proton exchange membrane (PEM) is the core, playing a key role. The PEM must show a high proton conductivity, a low electronic conductiv ity, thermal stability, low fuel permeability, good mechanical properties and low cost $[2,3]$. The first and most utilized membranes are based on expensive perfluorinated polymers, which operate only under fully hydrated conditions [4]. Many efforts are being done in order to replace this type of polymer, the current alternatives are: (i) modified perfluorinated com posites membranes, (ii) functionalized non fluorinated poly mers and related composite, and (iii) acid-base composite membrane $[5,6]$.

The second approach includes polymers with high me chanical and chemical stability, relatively high proton con ductivity, low cost and low permeability to the fuel. Some of them are: sulfonated polysulfone (SPSU) [7], sulfonated poly (ether ketone) (SPEK) [8], sulfonated poly (ether ether ketone) (SPEEK) [9], etc. Among these polymers, polysulfone is one of

\footnotetext{
- Corresponding author. Tel.: +34916249484.

E mail address: alvar@ing.uc3m.es (A. Varez).
} 
the preferred material due to its low cost, high thermal sta bility, and easy availability [10]. In addition, this polymer has been easily sulfonated with various sulfonating agents giving excellent proton conducting membranes.

Although, incorporations of inorganic fillers, such as, $\mathrm{TiO}_{2}$, $\mathrm{ZrO}_{2}$, phosphotungistic acid, leads to an increase in some properties of the virgin polymer [1,9,11-13], however clays are the most promising reinforcement materials due to they can easily be exfoliated to individual platelets inducing extremely large surfaces and interface between the filler and the poly mer matrix. These lamellar solids are used to increase the mechanical properties, decrease the fuel and water perme ability [14], and, due to their hygroscopic properties, maintain humidity inside the membrane [13].

In this sense, LDHs, also called anionic clays or hydrotalcite like compounds, exhibit certain specific advantages (purity, crystallinity and particle size control, easy functionalization), which are lacking in layered silicates type nanoclays. LDHs constitute a large family of inorganic materials, with the gen eral formula $\left[\mathrm{M}^{2+}{ }_{1 \times} \mathrm{M}^{3+}{ }_{\mathrm{x}} \cdot(\mathrm{OH})_{2}\right]\left(\mathrm{A}^{n}\right)_{\mathrm{x} / \mathrm{n}} \cdot \mathrm{mH}_{2} \mathrm{O}$, where $\mathrm{M}^{2+}$ is a divalent cation such as $\mathrm{Mg}, \mathrm{Ni}, \mathrm{Zn}, \mathrm{Cu}$, and $\mathrm{M}^{3+}$ is a trivalent cation such as $\mathrm{Al}, \mathrm{Cr}, \mathrm{Fe}, \mathrm{V}$ or $\mathrm{Ga}$; $x$ is a value that determines the layer charge density and the anion exchange capacity, ranges between 0.2 and 0.4. $A^{n}$ is an exchangeable anion with formal charge $n[15,16]$.

In this work, we disclose the preparation of LDH/SPSU membranes by the casting method using dimethylacetamide as solvent. The LDH used was $\mathrm{Zn}, \mathrm{Al} \mathrm{NO}_{3}$ in order to minimize the basic properties of this kind of compounds, and was prepared by the coprecipitation method. The polysulfone was sulfonated using chlorotrimethylsilane as sulfonating agent, different ratios PSU: chlorotrimethylsilane were used. The degree of dispersion of the LDH particles and the type of the polymeric membranes obtained were studied by $\mathrm{X}$ ray diffraction (XRD). The interactions between LDH and SPSU were discussed on the basis of the FTIR spectroscopy data. The Water Uptake Mea surements were used as a quantitative measure of membrane performance in fuel cells application. Performance of a mem brane is dependent on proton conductivity, which in turn often depends on its water content. High proton conductivity is supported by high level of water uptake; at the same time, it is also a sign of low dimensional stability as water influences the polymer microstructure and mechanical properties. The ther mal stability was determined by TGA analysis and electro chemical impedance spectroscopy (EIS) was used to study the membranes electrical properties. The EIS measurements were carried out with the membranes in contact with $\mathrm{HCl}$ solutions at different concentrations. Results showed a clear dependence of the membrane electrical resistivity with the sulfonation degree and the amount of the LDH added.

\section{Experimental}

\subsection{Materials}

The reagents, $\mathrm{Zn}\left(\mathrm{NO}_{3}\right)_{2} \cdot 6 \mathrm{H}_{2} \mathrm{O}, \mathrm{Al}\left(\mathrm{NO}_{3}\right)_{3} \cdot 9 \mathrm{H}_{2} \mathrm{O}, \mathrm{NaOH}$ were

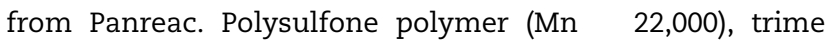
thylsilyl chlorosulfonate $\left(\mathrm{Si}\left(\mathrm{CH}_{3}\right)_{3} \mathrm{SO}_{3} \mathrm{Cl}, 99 \%\right)$ and the sol vents, N,N dimethylacetamide $\left(\mathrm{CH}_{3} \mathrm{C}(\mathrm{O}) \mathrm{N}\left(\mathrm{CH}_{3}\right)_{2}\right.$, DMAc) and
1,2 dichlorethane $\left(\mathrm{C}_{2} \mathrm{H}_{4} \mathrm{Cl}_{2}\right.$, DCE), were supplied by Aldrich. All of them were used without further purification.

\subsection{Preparation of the $\mathrm{Zn}, \mathrm{Al}-\mathrm{NO}_{3} \mathrm{LDH}$}

The LDH selected was $\left[\mathrm{Zn}_{1}{ }_{x} \mathrm{Al}_{x}(\mathrm{OH})_{2}\right]\left(\mathrm{NO}_{3}\right)_{x} 0.8 \mathrm{H}_{2} \mathrm{O}\left(\begin{array}{ll}x & 0.33\end{array}\right)$ due to the lower basicity. The powder was prepared by the co precipitation method [17]. A first solution was prepared by dissolving $\mathrm{Zn}\left(\mathrm{NO}_{3}\right)_{2} \cdot 6 \mathrm{H}_{2} \mathrm{O}$ and $\mathrm{Al}\left(\mathrm{NO}_{3}\right)_{3} \cdot 9 \mathrm{H}_{2} \mathrm{O}$ in $250 \mathrm{~mL}$ of water with a total $\mathrm{Zn} / \mathrm{Al}$ concentration of $0.6 \mathrm{~mol} / \mathrm{L}$ and a $\mathrm{Zn}$ :Al molar ratio of 2. A second solution was prepared by dissolving $\mathrm{NaOH}$ in $800 \mathrm{~mL}$ of water $(\mathrm{NaOH}$ concentration $1 \mathrm{~mol} / \mathrm{L}$ ). Both solutions were added drop wise to decarbo nated water in a 3 neck vessel, with stirring and the $\mathrm{pH}$ was maintained at a value of 8.0. The slurry was aged for $12 \mathrm{~h}$ at $40{ }^{\circ} \mathrm{C}$ with stirring. In order to minimize contamination with atmospheric $\mathrm{CO}_{2}$, the reaction was carried out under a ni trogen purge. Prepared powder was characterized by XRD and FTIR techniques.

\subsection{Sulfonation of the polysulfone}

The PSU was sulfonated according to a procedure described by Chao et al. [18]. The dried PSU (20 g) was dissolved in $100 \mathrm{~mL}$ anhydrous 1,2 dichlorethane in a three neck flask equipped with mechanical stirrer, condenser and nitrogen purge inlet which carries the gaseous $\mathrm{HCl}$ generated by the substitution. The resulting solution was purged with nitrogen for $1 \mathrm{~h}$ and chlorotrimethylsilane diluted in $20 \mathrm{~mL}$ 1,2 dichloroethane was added to the solution, dropwise for $30 \mathrm{~min}$. The resulting so lution was vigorously stirred for $24 \mathrm{~h}$ at room temperature. After reaction was completed, SPSU was isolated from the solution by precipitation with methanol, and then was washed with deionized water for several times and dried to constant weight. Two molar ratio of PSU:TMSCS were pre pared, 1:1 and 1:3. In case of higher TMSCS content, the sul fonated polymer produced was water soluble.

\subsection{Membrane preparation}

Dried sulfonated polysulfone was dissolved (5\% wt) in dime thylacetamide (DMAc), and the resulting solution was filtered. To prepare the composite membranes the LDH particles were suspended in a SPSU DMAc solution during $2 \mathrm{~h}$ with me chanical stirring and then in an ultrasonic bath for an addi tional hour. The membranes were cast on a Petri dish, using the LDH polymer solution, and dried at $60{ }^{\circ} \mathrm{C}$ during $12 \mathrm{~h}$. Finally, the membranes were washed with distillate water. The amount of LDH incorporated in the membranes was from 1 to $5 \mathrm{wt} \%$ of the total mass ( $\mathrm{LDH}+$ polymer). The thickness of the resulting membranes was around $100 \mu \mathrm{m}$.

\subsection{Characterization and measurements}

Powder X ray diffraction patterns were recorded in a X'Pert Philips instrument using $\mathrm{Cu} \mathrm{K} \alpha$ radiation $(\lambda \quad 1.54050 \AA)$.

The FTIR spectra were recorded in a Perkin Elmer Spec trum GX instrument, using $\mathrm{KBr}$ pellets; 100 spectra (recorded with a nominal resolution of $4 \mathrm{~cm}^{1}$ ) were averaged to improve the signal to noise ratio. 
Thermogravimetric analyses were carried out in TG 7 instrument from Perkin Elmer. The sample was heated from 50 to $900{ }^{\circ} \mathrm{C}$ in flowing nitrogen, at a heating rate of $10{ }^{\circ} \mathrm{C} \min { }^{1}$.

Water uptake of sulfonated polysulfones and LDH/SPSU composites membranes were determined from the difference between the dry and swollen membranes. A membrane of $3.8 \mathrm{~cm}^{2}$, was weighed dry and immersed in an excess of distilled water for $24 \mathrm{~h}$ at room temperature and at higher temperatures $60,80{ }^{\circ} \mathrm{C}$ for $2 \mathrm{~h}$. Then, the membrane was removed wiped and weighed $\left(\mathrm{W}_{\text {wet }}\right)$. Finally, the membrane was dried overnight at $80^{\circ} \mathrm{C}$ in an oven, and after was weighed again $\left(\mathrm{W}_{\mathrm{dry}}\right)$. The percentage of water absorbed was calculated using the following equation.

Water uptake $(\%) \quad\left(\mathrm{W}_{\text {wet }} \quad \mathrm{W}_{\text {dry }}\right) \times 100 / \mathrm{W}_{\text {dry }}$

For electrical characterization we have used a test cell constituted by two half cells separated by two $O$ rings where membrane was placed. A conventional electrochemical setup of four electrodes was used for these measurements involving two saturated $\mathrm{Ag} / \mathrm{AgCl}$ electrodes as reference electrodes and two platinum electrodes as secondary electrodes. Impedance spectroscopy (IS) measurements were carried using an impedance analyzer (Solartron 1260) together an electro chemical interface (Solartron 1287). The measurements were carried out at room temperature in the frequencies range of $0.1-10^{5} \mathrm{~Hz}$, by applying a $\pm 10 \mathrm{mV}$ amplitude sinusoidal wave perturbation, close to the resting membrane potential. Six different $\mathrm{HCl}$ solutions $\left(1 \times 10^{3} \leq \mathrm{c} \leq 0.1 \mathrm{M}\right)$ were tested. The solutions on both sides of the membrane have the same concentration. Before measurement, membranes were immersed for $12 \mathrm{~h}$ in a solution of the appropriated $\mathrm{HCl}$ concentration.

\section{Results and discussion}

\subsection{Polysulfone sulfonation}

Qualitative polysulfone sulfonation was confirmed using FTIR spectroscopy and termogravimetrical analysis.

In Fig. 1a the FTIR spectra for the pristine polysulfone (PSU) and sulfonated polysulfone in different amount (SPSU11 and SPSU13) are displayed. In the sulfonated samples a new broad band is recorded at $3400 \mathrm{~cm}^{1}$, assigned to the stretching $\mathrm{O}-\mathrm{H}$ vibration of the $-\mathrm{SO}_{3} \mathrm{H}$ group. However, this band is not enough to confirm the sulfonation process, because some moieties of water bonded to the hydrophilic sulfonic groups, which was not totally removed by the drying process, lead this intense band. The sulfonation process is confirmed by the presence of the shoulder, around $1030 \mathrm{~cm}^{1}$, together the peak located around $1014 \mathrm{~cm}^{1}$ and assigned to the symmetric stretching vibration of the diphenyl ether unit [19]. The shoulder represent the symmetric stretching of $-\mathrm{SO}_{3} \mathrm{H}$ group. This shoulder is more pronounced in the SPSU13 sample, indicating the increase in the sulfonation degree. In this polymer, the adsorption band due to the ether group overlaps to the characteristic band associated to the asymmetric
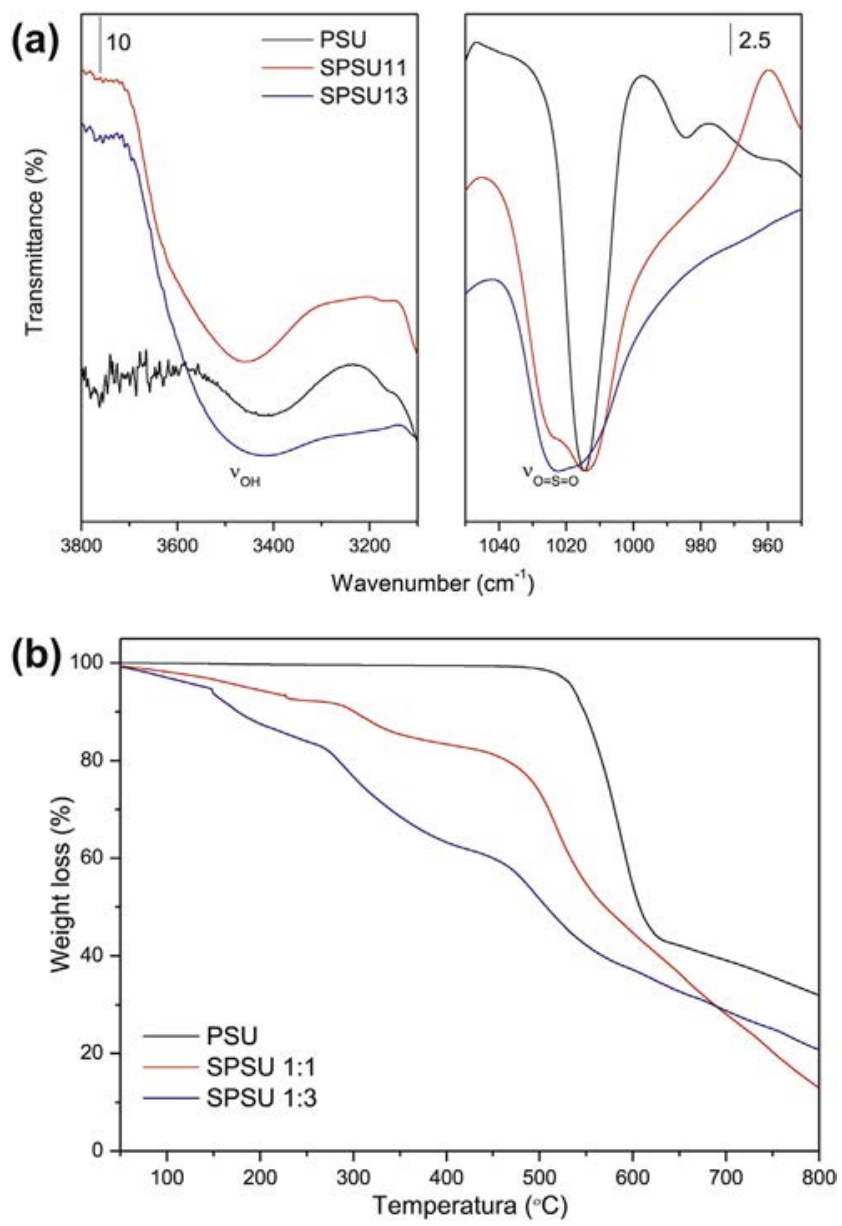

Fig. 1 - (a) FTIR spectra of PSU, SPSU11 and SPSU13 among the regions: $3800-3100 \mathrm{~cm}^{-1}$ and $1050-950 \mathrm{~cm}^{-1}$. All spectra were normalized for comparison (vertical bar indicate the scale of $y$-axis). (b) Thermogravimetric analysis for polysulfone (PSU) and sulfonated polysulfone in different degree (SPSU11 and SPSU13).

stretching vibrations of $-\mathrm{SO}_{3} \mathrm{H}$ group, which appears at $1350-1150 \mathrm{~cm}^{1}$ [20].

The thermogravimetric analysis of the PSU and SPSU samples, recorded in flowing nitrogen, is shown in Fig. 1b. The thermal degradation of PSU takes place in only one step be tween 525 and $600^{\circ} \mathrm{C}$, while for the SPSU at least 3 steps can be distinguished in the TGA. This also has been reported by other groups [7,21,22]. The first weight loss (up to $250{ }^{\circ} \mathrm{C}$ ) was assigned to evaporation of residual solvent and to the desorption of water bonded to hydrophilic sulfonic groups, which was not totally removed by the drying process. The weight loss between 250 and $440{ }^{\circ} \mathrm{C}$ is associated to the loss of sulfonic acid $\left(-\mathrm{SO}_{3} \mathrm{H}\right)$ groups. Finally the weight loss over $440^{\circ} \mathrm{C}$ is associated to the polymer main chain decomposition. As the sulfonation degree increases the onset of each loss weight takes places at lower temperature indicating that sul fonation has a negative effect on the polymer thermal stability and the increase in the sulfonation degree leads less thermal stability in the polymer. 


\subsection{Physical characterization of nanocomposites}

\subsubsection{X-ray diffraction}

The XRD patterns of the $\mathrm{Zn}, \mathrm{Al} \mathrm{NO} \mathrm{NO}_{3} \mathrm{LDH}$ powder, SPSU11 membrane and the LDH/SPSU11 composite membranes with different LDH contents (1, 2 and 5\% wt) are displayed in Fig. 2a. The very broad peak at $19.7^{\circ}(2 \theta)$ associated to the PSU in dicates the low crystallinity of the polymer. In the case of composite membranes the main diffraction peak, $d_{003}$, of the $\mathrm{Zn}, \mathrm{Al} \mathrm{NO}_{3} \mathrm{LDH}\left(d_{003} \quad 9 \AA, 2 \theta \quad 10.1^{\circ}\right)$ is absent in the XRD patterns of samples with 1 and 2 wt\% of LDH and only it is observed in the highest loaded composite membrane (labeled as arrows in Fig. 2a). This result could be expected for samples containing low amount of $\mathrm{LDH}$, due to the low concentration and low crystallinity. When the LDH content increases up to $5 \mathrm{wt} \%$, two very weak and broad diffraction peaks appear at $2 \theta \approx 9.4$ and $10^{\circ}$, one of them could correspond to the main diffraction peak of $\mathrm{Zn}, \mathrm{Al} \mathrm{NO} \mathrm{NDH}_{3}\left(d_{003}\right)$. On the other hand, for composite membranes with 2 and $5 \%$ of $\mathrm{LDH}$, also appears a new peak at $2 \theta \approx 5.5-6^{\circ}$ that could be associated to the intercalation of the part of the polymer between the interlayer of the LDH $[23,24]$.

\subsubsection{FT-IR spectroscopy}

The FT IR was, also, used in order to determinate the specific interaction of LDH/SPSU. The position of the shoulder corre sponding symmetric stretching vibration of the sulfonate group band is very sensitive to the local environment of the sulfonate anion [19,25], e.g. hydration by moisture or hydrogen bonding by a second component in a polymer blend, so that any interaction would shift the anion symmetric stretching vibration to lower frequencies (higher wave number). In Fig. 2b FT IR spectra of the SPSU11, SPSU11 1\% LDH and SPSU11 5\%LDH are displayed in the region $1100-950 \mathrm{~cm}^{1}$. The shoulder is shifted to higher wave number, indicating weak interactions between the hydroxyl
LDH layer and the sulfonic group, probably hydrogen bonding. Furthermore the intensity of this shoulder increases as the content of LDH, indicating major interaction between the LDH and the SPSU.

\subsubsection{Thermal stability}

In order to investigate the effect of the LDH in the thermal stability of the LDH/SPSU composites TGA was performed (Fig. 3). Two behaviors can be observed depending on the sulfonation degree. The presence of LDH in the SPSU11 membrane basically does not modify the thermal behavior of the film (Fig. 3a). However in the case of the SPSU13 (Fig. 3b) the main effect of introducing the LDH nanoparticles was a significant displacement of, basically, all degradation peaks, improving the thermal stability of the polymer. This effect is associated to the thermal characteristic of the LDH which could be ascribed to the hindering role of the LDH particles on the diffusion of oxygen and volatile products throughout the composite materials [26]. The thermal stability improves with the LDH, but an optimum fraction exists beyond which the thermal stability begins to deteriorate. In the SPSU13 when the LDH content increases (samples with 5\%) the thermal degradation temperature seems decrease. This behavior has been previously reported for other LDH polymer system $[27,28]$ and is due to the fact that the high content of LDH can catalyze the degradation of polymer.

\subsubsection{Water uptake measurements}

In Fig. 4, the water uptake at different temperatures (25, 60 and $80{ }^{\circ} \mathrm{C}$ ) of the different membrane tested is compared. After sulfonation of PSU, the water uptake increases as a conse quence of the hydrophilic character of acid groups. Unlike other system, the amount of water absorbed did not increase with the temperature [13]. In the case of composite mem branes, and at the same sulfonic acid content, water uptake of the different SPSU/LDH composite membranes is lower than
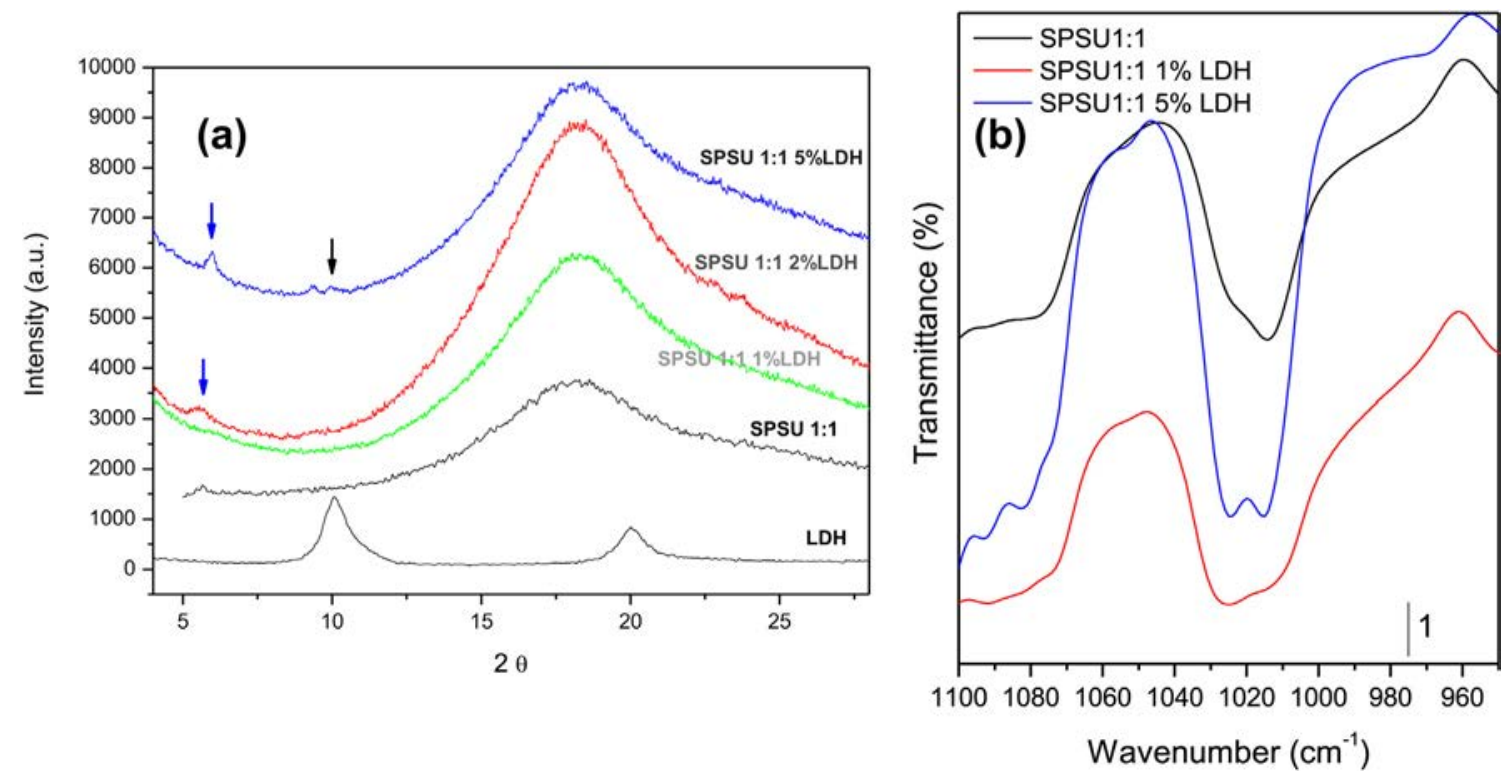

Fig. 2 - (a) PXRD patterns from the LDH, SPSU11 and the different LDH/SPSU11 membranes. (b) FT-IR spectra of SPSU11 and composites with 1 and $5 \%\left(1100-950 \mathrm{~cm}^{-1}\right.$ range). Vertical bar indicate the scale of $y$-axis. 

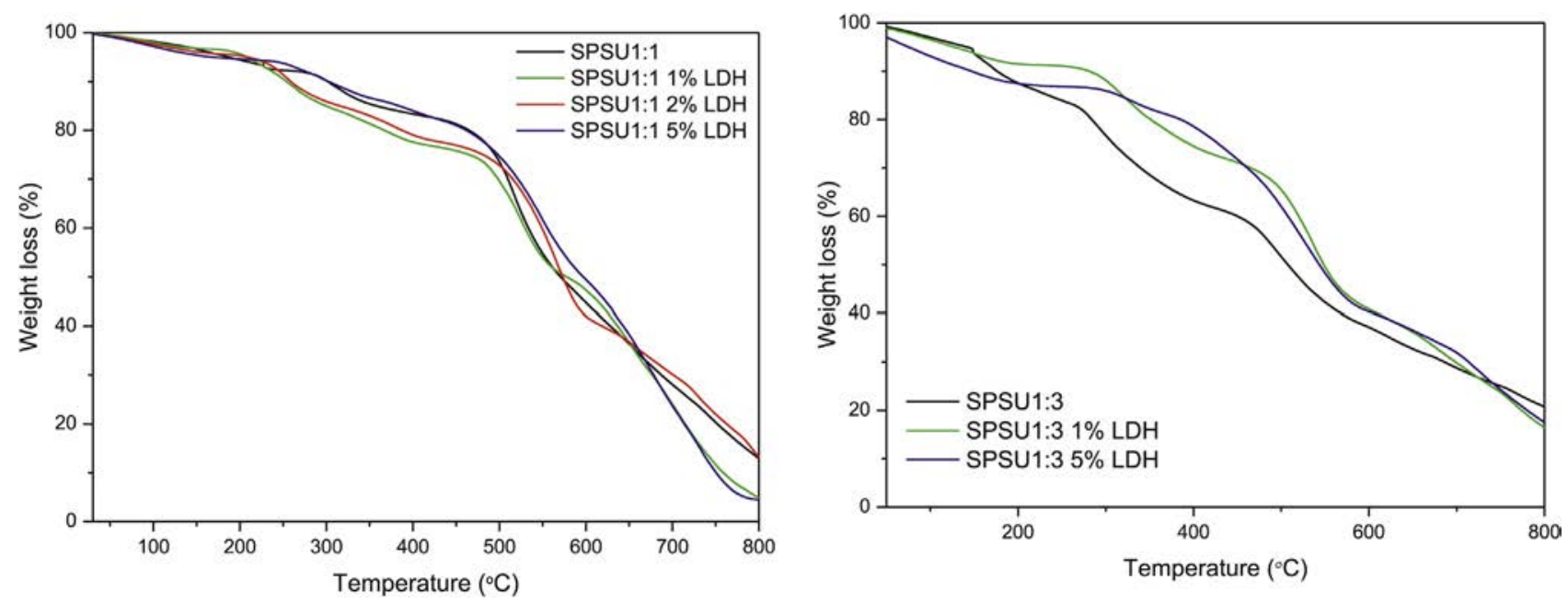

Fig. 3 - TGA curves of the sulfonated polysulfone in different degree (SPSU11 and SPSU13) and their respective LDH composites.

SPSU membrane. This behavior was found in other composite membrane system $[29,30]$ and it was attributed to the reduction of the free volume and swelling ability, however this argument cannot be admitted in this case because the water uptake increases with the amount of LDH. This situation is compatible with the formation of hydrogen bonding between sulfonic acid group and the hydrotalcite type compound. Regarding to the evolution of water uptake of composite membranes with the temperature we observed, as expected, an increase of water absorbed with the temperature.

\subsubsection{Electrochemical impedance spectroscopy}

The study of the electric properties of the membranes was performed using electrochemical impedance spectroscopy (EIS). Prepared membranes were placed in contact with the different acid solutions and they were equilibrated during a specific time period in contact with the electrolyte. After this,

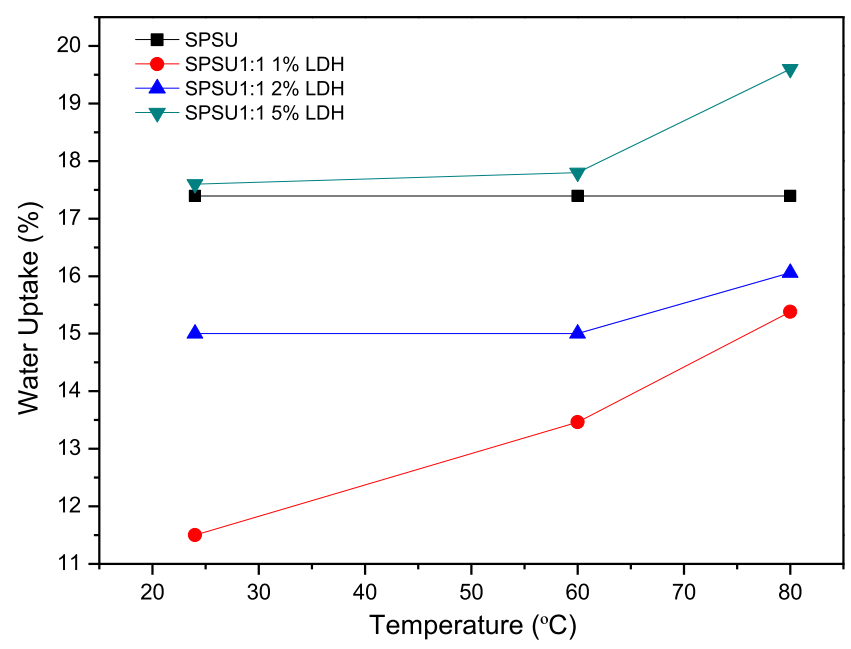

Fig. 4 - Water uptake measurements at different temperatures $\left(25,60\right.$ and $\left.80^{\circ} \mathrm{C}\right)$ for SPSU and SPSU composites. impedance spectroscopy measurements were carried out in a four electrode electrochemical cell. Fig. 5a shows the Nyquist plot ( $Z^{\prime}$ vs $Z^{\prime \prime}$ ) for SPSU11 with $1 \%$ of LDH in contact with different $\mathrm{HCl}$ solutions. All the spectra present clearly two semicircles, which change with the $\mathrm{HCl}$ concentration of solutions. The first semicircle (high frequency arc (HFA)) could be associated to the membrane capacitance (or constant phase element of the membrane) acting in parallel with its resistance. The low frequency arc (LFA) is clearly deformed and is associated to diffusion of electroactive species through the membrane [31]. In all cases, the high frequency semicircle does not intercept the origin of the plot, indicating the presence of a resistive element in series with the other two processes. This resistive element should be related to the electrolyte.

The experimental data for each membrane and each $\mathrm{HCl}$ concentration were fitted with commercial software [32] to different equivalent circuits. The best fitting was obtained for the equivalent circuit showed in the inset of Fig. 5. In this circuit, $R_{s}$ represents the resistance of the electrolytic solution, $R_{i}$ usually is related to the ionic resistance of the membrane, $C_{g}$ is assigned to the geometric capacitance of the membrane, and $Z_{w s}$ the Warburg impedance in diffusion layer with finite thickness. From the fitting, the values of the different circuit parameters were determined. As expected the resistivity associated to the membrane decreases with amount of $\mathrm{HCl}$ (Fig. 5b). This behavior has been also observed in poly(ether ether sulfone) [33] and is attributed to the concentration dependence of the electrolyte solution embedded in the membrane matrix.

Fig. $6 \mathrm{a}$ shows the evolution of the impedance plots as a function of the amount of LDH added to the membrane. The diameter of the high frequency arcs decreases with the amount of LDH, indicating an improving of the proton conductivity with the amount of inorganic powder. The SPSU/ LDH nanocomposite membranes have a better electrical behavior than those membrane based on the SPSU matrix alone (blank membrane), showing the lowest electrical 

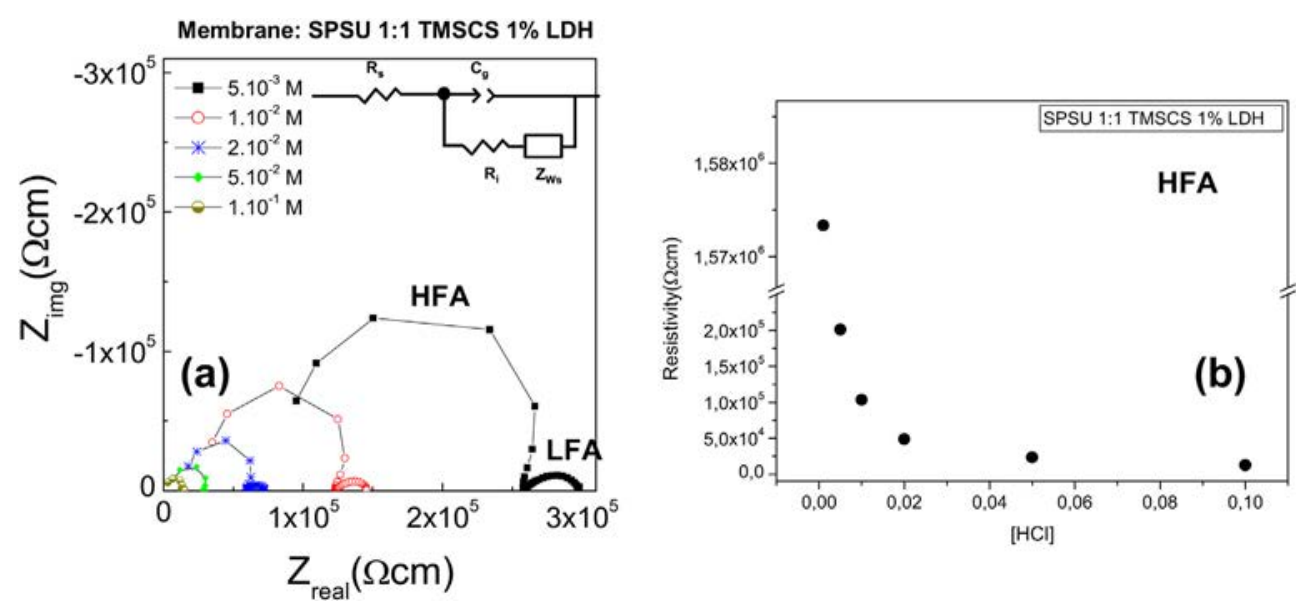

Fig. 5 - (a) Complex Impedance plot for the membrane composite with $1 \%$ of LDH at different $\mathrm{HCl}$ concentration. The equivalent circuit used for fitting is also displayed in the inset. (b) Evolution of the membrane resistivity with the $\mathrm{HCl}$ concentration.
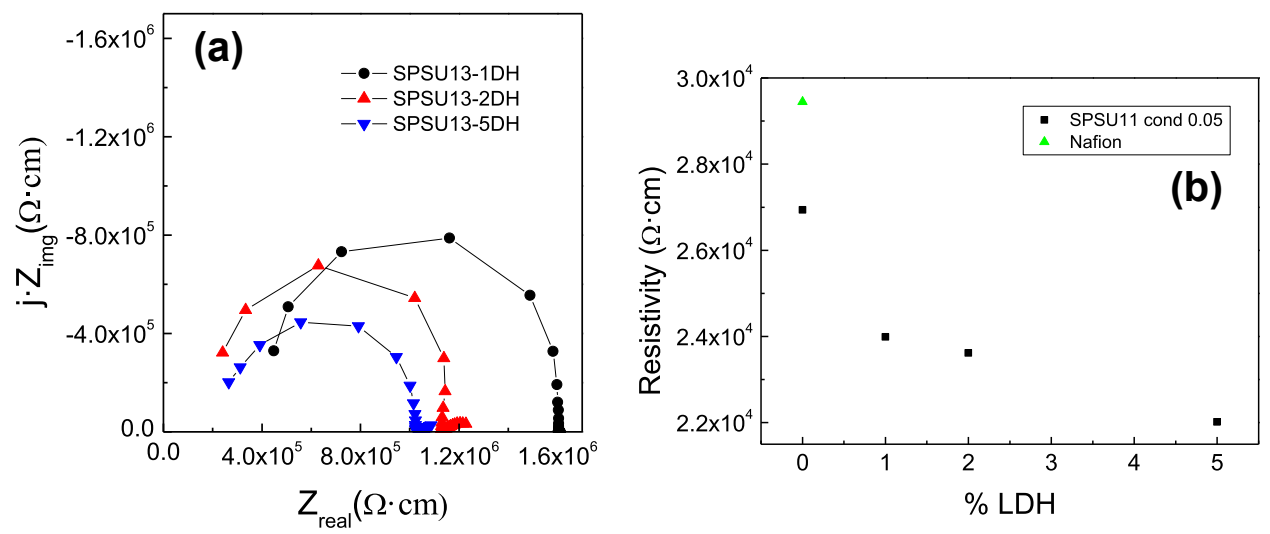

Fig. 6 - (a) Nyquist plot for three composite membranes with different percentage of LDH (1, 2 and $5 \%$ ) (c = 0.05 M HCl). (b) Resistivity of the membrane vs \%LDH. Values are also compared with nafion membrane.

resistivity the SPSU with a $5 \%$ wt of LDH (Fig. 6b). Even these values are lower than that of Nafion. These results indicate that this kind of nanocomposites membranes is very promising for being applied as proton-exchange membranes.

\section{Conclusions}

A series of sulfonated polysulfone/layered double hydroxide nanocomposite membranes were prepared using solvent casting technique. The $\mathrm{Zn}, \mathrm{Al}-\mathrm{NO}_{3} \mathrm{LDH}$ powder was obtained by the coprecipitation method. Polysulfone was sulfonated with trimethylsilyl chlorosulfonate in 1,2 dichloroethane at room temperature and different sulfonation degrees were obtained. The sulfonation of PSU reduces the thermal stability of the polymer. However the introduction of LDH powders improved the thermal behavior, especially in the case of the samples with higher sulfonation degree. The introduction of LDH clearly affects the properties of SPSU membranes, particularly their water uptake, electrical and transport parameters. Electrochemical characterization of the membranes by EIS shows behaviors that depend on the concentration of both the electrolyte and membrane. The electrical resistivity of membrane (inversely connected to the proton conductivity) is closely related with both the concentration of $\mathrm{HCl}$ in contact with membrane and with the layered double hydroxide nanocomposite. This work demonstrates that LDH-composites membranes are promising materials for proton-exchange process, due to membrane transport are quite similar to those of the best PEM system.

\section{Acknowledgments}

Authors thanks financial support received from the regional government (Comunidad de Madrid through MATERYENER S2009 PPQ-1626), and Spanish Government, MICINN (MAT201019837-CO6). 


\section{R E F E R E N C E S}

[1] Unnikrishnan L, Mohanty S, Nayak SN, Singh N. Synthesis and characterization of polysulfone/clay nanocomposite membranes for fuel cell application. J Appl Polym Sci 2012;124:E309 18.

[2] Thanganathan U, Nogami M. Synthesis of mixed composite membranes based polymer/HPA: electrochemical performances on low temperature PEMFCs. J Membr Sci 2012;411 412:109 16.

[3] Hickner MA, Ghassemi H, Kim YS, Einsla BR, McGrath JE. Alternative polymer systems for proton exchange membranes (PEMs). Chem Rev 2004;104:4587 612.

[4] Peighambardoust SJ, Rowshanzamir S, Amjadi M. Review of the proton exchange membranes for fuel cell applications. Int J Hydrogen Energy 2010;35:9349 84.

[5] Jannasch P. Recent developments in high temperature proton conducting polymer electrolyte membranes. Curr Opin Colloid Interface Sci 2003;8:96 102.

[6] Roziere J, Jones DJ. Non fluorinated polymer materials for proton exchange membrane fuel cells. Ann Rev Matter Res 2003;33:503 5 .

[7] Lufrano F, Squadrito G, Patti A, Passalacqua E. Sulfonated polysulfone as promising membranes for polymer electrolyte fuel cells. J Appl Polym Sci 2000;77:1250 7.

[8] Sangeetha D. Sulphonated poly(ether ether ketone) proton exchange membranes for fuel cell applications. Int J Polym Mater 2007;56:535 48.

[9] Kim TW, Sahimi M, Tsotsis TT. Preparation and characterization of hybrid hydrotalcite sulfonated polyetheretherketone (SPEEK) cation exchange membranes. Ind Eng Chem Res 2009;48:9504 13.

[10] Zhu Y, Manthiram A. Synthesis and characterization of polysulfone containing sulfonated side chains for direct methanol fuel cells. J Power Sources 2011;196:7481 7.

[11] Navarra MA, Croce F, Scrosati B. New, high temperature superacid zirconia doped Nafion composite membranes. J Mater Chem 2007;17:3210 5.

[12] Wu Z, Sun G, Jin W, Hou H, Wang S, Xin Q. Nafion and nanosize $\mathrm{TiO}_{2} \quad \mathrm{SO}_{4}^{2}$ solid superacid composite membrane for direct methanol fuel cell. J Membr Sci 2008;313:336 43 .

[13] Unnikrishnnan L, Madamana P, Mohanty S, Nayak SK. Polysulfone/C30B nanocomposite membranes for fuel cell applications: effect of various sulfonating agents. Polym Plastics Technol Eng 2012;51:568 77.

[14] Smita B, Sridhar S, Khan AA. Proton conducting composite membranes from polysulfone and heteropolyacid for fuel cell applications. J Polym Sci B 2005;43:1538 47.

[15] Cavani F, Trifiró F, Vaccari A. Hydrotalcite type anionic clays: preparation, properties and applications. Catal Today 1991;11:173 302.

[16] Rives V. Layered double hydroxides: present and future. New York: Nova Science Publishers, Inc.; 2001.

[17] Gardner E, Pinnavaia TJ. On the nature of selective olefin oxidation catalysts derived from molybdate and tungstate intercalated layered double hydroxides. Appl Catal A 1998;167:65 74.
[18] Chao HS, Kelsey DR. Process for preparing sulfonated poly(arylether)resins. US patent number 4,625,000; November 25, 1986.

[19] Deimedea VA, Fragou KV, Koulouri EG, Kallitsis JK, Voyiatzis GA. Miscibility behavior of polyamide 11/ sulfonated polysulfone blends using thermal and spectroscopic techniques. Polymer 2000;41:9095 101.

[20] Linares A, Benavente R. Effect of sulfonation on thermal, mechanical and electrical properties of blends based on polysulfones. Polym J 2009;41:407 15.

[21] Park HB, Shin HS, Lee YM, Rhim JW. Annealing effect of sulfonated polysulfone ionomer membranes on proton conductivity and methanol transport. J Membr Sci 2005;247:103 11.

[22] Guan R, Zou H, Lu D, Gong C, Liu Y. Polyethersulfone sulfonated by chlorosulfonic acid and its membrane characteristics. Eur Polym J 2005;41:1554 60.

[23] Uhl FM, Davuluri SP, Wong SC, Webster DC. Polymer films possessing nanoreinforcements via organically modified layered silicate. Chem Mater 2004;16:1135 42.

[24] Anadao P, Sato LF, Wiebeck H, Valenzuela Díaz FR. Montmorillonite as a component of polysulfone nanocomposite membranes. Appl Clay Sci 2010;48:127 32.

[25] Lu X, Weiss RA. Development of miscible blends of bisphenol A polycarbonate and lightly sulfonated polystyrene ionomers from intrapolymer repulsive interactions. Macromolecules 1996;29:1216.

[26] Sur GS, Sun HL, Lyu SG, Mark JE. Synthesis, structure, mechanical properties and thermal stability of some polysulfone/organoclay nanocomposites. Polymer 2001;42:9783 9.

[27] Herrero M, Benito P, Labajos FM, Rives V, Zhu YD, Allen GC, et al. Structural characterization and thermal properties of PA6.6/Mg, Al/Ad LDH nanocomposites obtained by solid state polymerization. J Solid State Chem 2010;183:1645 51.

[28] Du L, Qu B, Zhang M. Thermal properties and combustion characterization of nylon 6/MgAl LDH nanocomposites via organic modification and melt intercalation. Polym Degrad Stab 2007;92:497 502.

[29] Kalappa P, Lee JH. Proton conducting membranes based on sulfonated poly(ether ether ketone)/ $\mathrm{TiO}_{2}$ nanocomposites for a direct methanol fuel cell. Polym Int 2007;56:371 5 .

[30] Devrim Y, Erkan S, Baç N, Eroglu I. Preparation and characterization of sulfonated polysulfone/titanium dioxide composite membranes for proton exchange membrane fuel cells. Int J Hydrogen Energy 2009;34:3467 75.

[31] Aranda P, Galván JC, Casal B, Ruiz Hitzky E. Electrochemical characterization of composite membranes based on crown ethers intercalated into montmorillonite. Colloid Polym Sci 1994;272:712 20.

[32] ZView for Windows, impedance/gain phase graphing and analysis software. Southern Pines, NC, USA: Scribner Associates Inc.; 2010.

[33] Benavente J, Cañas A, Ariza MJ, Lozano AE, De Abajo J. Electrochemical parameters of sulfonated poly ether ether sulfone/membranes in $\mathrm{HCl}$ solutions determined by impedance spectroscopy and membrane potential measurements. Solid State Ionics 2001;145:53 60. 